\title{
An important first step in the evaluation of venous thromboembolism after pulmonary resection
}

\author{
Thomas Ng, MD, FRCSC, FACS
}

\author{
From the Department of Surgery, The Warren Alpert Medical School of Brown University, Providence, RI. \\ Disclosures: Author has nothing to disclose with regard to commercial support. \\ Received for publication Aug 26, 2015; accepted for publication Aug 27, 2015; available ahead of print Oct 15, \\ 2015. \\ Address for reprints: Thomas Ng, MD, FRCSC, FACS, 2 Dudley St, Ste 470, Providence, RI 02905 (E-mail: \\ tng@usasurg.org). \\ J Thorac Cardiovasc Surg 2016;151:45-6 \\ 0022-5223/\$36.00 \\ Copyright (C) 2016 by The American Association for Thoracic Surgery \\ http://dx.doi.org/10.1016/j.jtcvs.2015.08.100
}

Data from the American College of Surgeons Oncology Group Z0030 randomized trial and from large databases such as the Nationwide Inpatient Sample and Society of Thoracic Surgeons National Database have shown the incidence of venous thromboembolism (VTE) after major pulmonary resection to be $1 \%$ to $2 \%{ }^{1-3}$ Although VTE is uncommon after pulmonary resection, the consequences of this complication can be severe, as stated by Hachey and colleagues ${ }^{4}$ in this issue of the Journal. It is important to find accurate predictors of postoperative VTE, with the goal of lowering its incidence by initiating prolonged postoperative prophylaxis in high-risk patients, but at the same time avoid overtreatment, treatment risks, and costs.

The article by Hachey and colleagues ${ }^{4}$ provides a solid foundation to begin the evaluation of VTE after pulmonary resection. In this study, 232 patients undergoing anatomic pulmonary resection for lung cancer are retrospectively analyzed with regard to their Caprini VTE risk score. The Caprini VTE score has been used by other surgical specialties, but there are currently no published data to assess its utility in pulmonary resection. Their results ${ }^{4}$ show the incidence of VTE (ie, pulmonary embolism or deep venous thrombosis at 60 days) to be 5.2\% after pulmonary resection; a rate higher than that seen in larger series, ${ }^{1-3}$ perhaps due to the 60-day event period evaluated. In addition, the authors found that the Caprini score was associated with the incidence of postoperative VTE. Patients with a score of 0 to 4 had no VTE events, patients with a score of 5 to 8 had a $1.7 \%$ incidence of postoperative VTE, and patients with a score of 9 or greater had a $10.3 \%$ incidence of postoperative VTE. From these results, the authors then recommended no prophylaxis beyond hospitalization for low-risk patients (score, 0-4), 10 days of postoperative prophylaxis for moderate-risk patients (score, 5-8) and 30 days of postoperative prophylaxis for high-risk patients (score, 9 or greater).

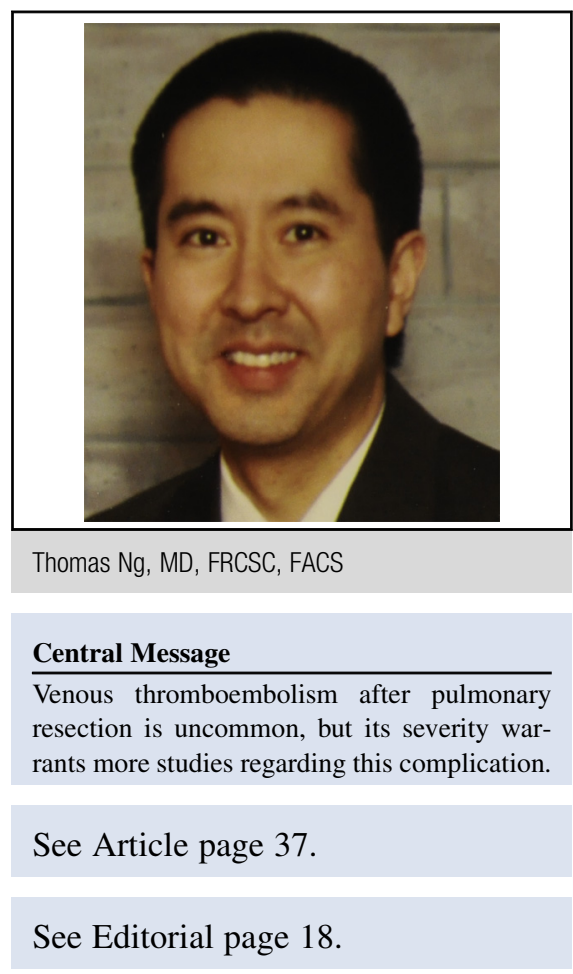

This study by Hachey and colleagues ${ }^{4}$ has several limitations, the major limitation being its retrospective nature. The Caprini VTE score, as shown in their Table $4,{ }^{4}$ contains several elements that can only be accurately assessed in a prospective manner. Data regarding complications of pregnancy, confined to bed more than 72 hours, family history of VTE, anticardiolipin antibody, and lupus anticoagulant cannot be obtained with any degree of accuracy by retrospective analysis. Second, the study excluded a large number of patients, up to one-fourth of the study population, many due to inadequate follow-up. Finally, no patients in the study received prolonged prophylaxis beyond that given in the hospital; therefore, the study provides no data to support their recommendations in their Figure $1^{4}$ regarding when and how long prophylaxis should be given. Certainly a prospective study is needed before their recommendations regarding prolonged postoperative prophylaxis can be accepted. To be meaningful, such a prospective study will need a large number of patients due to the low event rate of VTE, and will also need to involve the use of prolonged postoperative prophylaxis. 
Despite its limitations, the article by Hachey and colleagues ${ }^{4}$ provides an important first step in the study of VTE after pulmonary resection. The authors should continue this momentum and perform a well-designed prospective study to confirm their findings.

\section{References}

1. Scott WJ, Allen MS, Darling G, Meyers B, Decker PA, Putnam JB, et al. Video-assisted thoracic surgery versus open lobectomy for lung cancer: a secondary analysis of data from the American College of Surgeons Oncology Group Z0030 randomized clinical trial. J Thorac Cardiovasc Surg. 2010;139:976-81.
2. Paul S, Sedrakyan A, Chiu YL, Nasar A, Port JL, Lee PC, et al. Outcomes after lobectomy using thoracoscopy vs thoracotomy: a comparative effectiveness analysis utilizing the Nationwide Inpatient Sample database. Eur J Cardiothorac Surg. 2013;43:813-7.

3. Paul S, Altorki NK, Sheng S, Lee PC, Harpole DH, Onaitis MW, et al. Thoracoscopic lobectomy is associated with lower morbidity than open lobectomy: a propensity-matched analysis from the STS database. J Thorac Cardiovasc Surg. 2010;139:366-78.

4. Hachey KJ, Hewes PD, Porter LP, Ridyard DG, Rosenkranz P, McAneny D, et al. Caprini venous thromboembolism risk assessment permits selection for postdischarge prophylactic anticoagulation in patients with resectable lung cancer. J Thorac Cardiovasc Surg. 2016; 151:37-44.e1. 